\title{
ON THE BI-MODAL SOLUTION TO THE FUNDAMENTAL PROBLEM OF CHRISTOLOGY ${ }^{1}$
}

\author{
JEREMIAH JOVEN JOAQUIM \\ https:/ / orcid.org/0000-0002-8621-6413 \\ De la Salle University \\ Department of Philosophy \\ Manila, Metro Manila \\ Philippines \\ jeremiah.joaquin@dlsu.edu.ph
}

\author{
Article info \\ CDD: 200.9 \\ Keywords \\ Bi-Modal Solution \\ Chalcedon Doctrine \\ Christology \\ The Dual Nature of Christ
}

Received: 05.03.2021; Revised: 20.04.2021; Accepted: 04.05.2021

https://doi.org/10.1590/0100-6045.2021.V44N4.JJ

\begin{abstract}
In a recent paper, Jc Beall and A. J. Cotnoir proposed a bi-modal solution to the fundamental problem of Christology - the problem of reconciling the apparent contradiction implied by Christ's divine and human natures. According to their solution, the contradiction could be resolved if one takes Christ's dual nature as implying two different theological modal notions: one ranging over divine possibilities and the other over human possibilities. As a
\end{abstract}

${ }^{1}$ My thanks to Maxell Aranilla, Hazel T. Biana, Jc Beall, Ben Blumson, Mark Joseph Calano, Mark Anthony Dacela, Fides del Castillo, James Franklin, Brian Garrett, Michael Roland Flor Hernandez, Yujin Nagasawa, Raymond Girard Tan, the two anonymous referees of this journal, and the students of my Symbolic Logic and Philosophical Research classes to whom I've discussed this topic.

Manuscrito - Rev. Int. Fil. Campinas, v. 44, n. 4, pp. 83-92, Oct.-Dec. 2021. 
riposte, I argue that as novel and ingenious as Beall and Cotnoir's solution may be, it still fails to account for the very crux of the fundamental problem, viz., the true (modal) proposition about Christ being God-incarnate.

\section{The Fundamental Problem of Christology}

The fundamental problem of Christology stems from the Chalcedon doctrine about Christ's dual nature of being fully divine and fully buman. Richard Cross characterises the problem in terms of the question of how to consistently explain that "one and the same thing could be both divine (and thus, on the face of it, necessary, and necessarily omniscient, omnipotent, eternal, immutable, impassible, and impeccable) and human (and thus, on the face of it, have the complements of all these properties)" (Cross 2011, p. 453). For example, accepting that Christ is fully human and fully divine seems to lead to the contradictory conclusion that Christ is both mutable and immutable. The reasoning for this conclusion is pretty straightforward:

1 Christ is fully divine and fully human. [The Chalcedon doctrine]

2 Christ is fully divine. [from 1 via simplification]

3 Christ is fully human. [from 1 via simplification]

4 Christ is mutable (i.e., Christ can change). [from 3, entailed by the Chalcedon doctrine]

5 Christ is immutable (i.e., Christ cannot change). [from 3 , entailed by the Chalcedon doctrine]

6 So, Christ is both mutable and immutable (i.e., Christ can and cannot change). [from 4 and 5 via conjunction] 


\section{Beall and Cotnoir's Bi-Modal Solution}

There have been many attempts to address the fundamental problem of Christology throughout the centuries, and the work of Beall and Cotnoir (2020) is a recent addition to this ever-growing list. According to their bi-modal solution, to resolve the apparent contradiction implied by Christ's dual nature, "theologians must... consider whether distinctively theological modalities do important theological work" (Beall and Cotnoir, 2020, p. 6). For them, two sorts of "theological" possibilities naturally stem from Christ's dual nature. There are possibilities grounded in Christ's human nature and there are possibilities grounded in Christ's divine nature. Thus, a true modal proposition about Christ either belongs to the set of propositions about divine possibilities or to the set of propositions about human possibilities.

Beall and Cotnoir account for the logical behaviour of these theological modalities in terms of the standard pointbased (possible-worlds) semantics, where the set of worlds (or propositions), $W$ is divided into the set of divine possibilities, $D$ and the set of human possibilities, $H . \mathrm{R}^{\mathrm{d}}$ is the "divine accessibility relation" that picks out points in $D$ from a given world, while $\mathrm{R}^{\mathrm{h}}$ is the "human accessibility relation" that picks out points in $H$ from a given world.

Where " $A$ " denotes any proposition and " $\nabla_{d} A$ " and " ${ }_{h} A$ " represent " $A$ is divinely possible" and " $A$ is humanly possible", respectively, the truth valuation of these theological modalities will be as follows:

- $\diamond_{\mathrm{d}} \mathrm{A}$ is true at $w$ iff there's some $\mathrm{R}^{\mathrm{d}}$-accessible point $x$ at which $A$ is true.

- $\oslash_{\mathrm{d}} \mathrm{A}$ is false at $w$ iff for all $\mathrm{R}^{\mathrm{d}}$-accessible points $x, \mathrm{~A}$ is false at $x$. 
- $\quad \nabla_{\mathrm{h}} \mathrm{A}$ is true at $w$ iff there's some $\mathrm{R}^{\mathrm{h}}$-accessible point $x$ at which $\mathrm{A}$ is true.

- $\diamond_{\mathrm{h}} \mathrm{A}$ is false at $w$ iff for all $\mathrm{R}^{\mathrm{h}}$-accessible points $x$, is false at $\mathrm{x}$.

Beall and Cotnoir further define the corresponding notions of impossibilities in terms of logical negation, " " as follows:

- $\quad \sim \diamond_{\mathrm{d}} \mathrm{A}$ is true at $w$ iff $\vartheta_{\mathrm{d}} \mathrm{A}$ is false at $w$.

- $\quad \sim \nabla_{\mathrm{h}} \mathrm{A}$ is true at $w$ iff $\vartheta_{\mathrm{h}} \mathrm{A}$ is false at $w$.

In light of their proposed semantics, Beall and Cotnoir resolve the fundamental problem by revising premises 4 and 5 of the argument above as:

4a By virtue of Christ's human nature, Christ is mutable (i.e., $\diamond_{\mathrm{h}}$ (Christ changes)).

5a By virtue of Christ's divine nature, Christ is immutable (i.e., $\sim \oslash_{\mathrm{d}}($ Christ changes $\left.)\right)$.

As a consequence, the conclusion must be revised as:

6a So, by virtue of Christ's human nature, Christ is mutable and by virtue of Christ's divine nature, Christ is immutable (i.e., $\nabla_{\mathrm{h}}($ Christ changes) and $\sim \diamond_{\mathrm{d}}($ Christ changes $\left.)\right)$.

The upshot of Beall and Cotnoir's solution is quite clear. Since the accessible points that make " $\diamond_{h}$ (Christ changes)" true are different from the points that make " $\sim \nabla_{\mathrm{d}}($ Christ changes)" true, the contradictory conclusion of the fundamental problem could still be false; hence, would not follow from the starting premises. 


\section{A Riposte}

As novel and ingenious as Beall and Cotnoir's bi-modal solution may be, it still seems incomplete since it fails to fully explain the very heart of the fundamental problem of Christology, viz., the truth about the incarnate nature of Christ itself. The fundamental problem is not only the challenge of giving a consistent account of the logical implications of Christ's dual nature; it is also the challenge of accounting for true (modal) propositions about Christ, the Second Person of the Trinity, being God-incarnate. If this cannot easily and naturally be accommodated by the proposed bi-modal picture, then Beall and Cotnoir's solution is a non-starter, at least with respect to the crux of the fundamental problem itself.

To see this, consider the true proposition expressed by the sentence, "Christ is the incarnated Second Person of the Trinity", or simply, "Christ is God-incarnate". (Alternatively consider the implied modal proposition expressed by the sentence, "Possibly, Christ is God-incarnate".) ${ }^{2}$ Beall and Cotnoir tell us that the sentence implies that "a divine person has both a divine and a created nature" (Beall and Cotnoir, 2020 , p. 5). This means that some propositions of the same subject, Christ, are made true by the set of divine possibilities, $D$ (e.g. that Christ is immutable), while others are made true by the set of human possibilities, $H$ (e.g. that Christ is mutable). But what of the very proposition itself? Is the sentence, "(Possibly) Christ is God-incarnate" made true by propositions in $D$ or by propositions in $H$ ? $^{3}$

2 That is, given the T-axiom (of modal logic), "Possibly, Christ is God-incarnate" follows from "Christ is God-incarnate".

3 This is a natural question to ask since Beall and Cotnoir's proposed bi-modal solution has not said anything about how to 
If "(Possibly) Christ is God-incarnate" belongs to $D$, then the proposition expressed by the sentence, "Christ is both fully human and fully divine" must also belong to $D$. This is so since, given orthodox Christology, the latter is implied by the former, at least at a world that witnesses this modal claim. By a simple logical inference, however, the proposition, "Christ is fully human" must also belong to D. ${ }^{4}$ Thus, if Beall and Cotnoir are right that "(Possibly) Christ is Godincarnate" belongs to $D$, then, contra their proposed bi-modal solution, at least one proposition about Christ's human possibilities is made true not by his human but by his divine nature. Mutatis mutandis, if "(Possibly) Christ is Godincarnate" belongs to $H$, then at least one proposition about Christ's divine possibilities - viz., that Christ is fully divine is made true by his human and not by his divine nature.

Ultimately, then, if the proposed bi-modal solution has an account of what makes the sentence, "(Possibly) Christ is God-incarnate" true, then the solution seems self-defeating. On the other hand, if the proposed bi-modal solution fails to account for the truth of the sentence, "(Possibly) Christ is God-incarnate" (given its resources), then the solution is incomplete. Thus, with respect to a true modal proposition about Christ's incarnate nature, the bi-modal solution is either explanatorily self-defeating or incomplete.

assign propositions to modal sentences, and so it's not obvious that "(Possibly) Christ is God-incarnate" belongs to either set $D$ or $H$.

${ }^{4}$ As a referee of this journal has correctly pointed out, this "simple logical inference" presupposes a normal modal logic, where the inference from $\diamond(A \& B)$ to $(\nabla A \& \diamond B)$ is valid. Of course, there are non-normal modal logics where this inference fails. But since the proposed bi-modal solution used standard modal semantics (Beall and Cotnoir, 2020, p. 5), it is reasonable to assume that their solution permits this inference as well.

Manuscrito - Rev. Int. Fil. Campinas, v. 44, n. 4, pp. 83-92, Oct.-Dec. 2021. 


\section{Rejoinders and Further Objections}

Beall and Cotnoir might reply that the proposed bi-modal solution implies that only propositions about God as $\mathrm{He}$ is in Himself are in D. The proposition expressed by '(Possibly) Christ is God-incarnate', however, is dubiously about God as $\mathrm{He}$ is intrinsically. So, there would be no reason why the proposition expressed by "(Possibly) Christ is Godincarnate" should be in $D$.

This response, however, would not do. First, it must be pointed out that "(Possibly) Christ is God-incarnate" is about God the Son, the Second Person of the Trinity. The sentence might not be about God the Father but, given the theology of orthodox Christianity, we must at least grant that it is about the Trinitarian God intrinsically. Second, even if we grant that "(Possibly) Christ is God-incarnate" is not in D, then it must follow that it is in $H$. But not only does this goes against the doctrines of orthodox Christianity that professes that Christ is both fully divine and fully human, it also implies the paradoxical conclusion that at least one proposition about Christ's divine possibilities is made true by his human nature.

Beall and Cotnoir may respond that the bi-modal solution does not require that the set of theological possibilities be closed under logical consequence. That is, even if some complex modal sentence, say $\diamond_{\mathrm{d}}(\mathrm{A} \& \mathrm{~B})$ is made true by some proposition in $D$, the sentences entailed by it need not be so. For example, one of its entailed conjuncts, say A, need not be in $D$, since it might be made true by some point in $H$ instead. Accordingly, even if "Christ is both fully human and fully divine" logically entails "Christ is fully human", it does not necessarily follow that if the former is in $D$, the latter 
must be in $D$ as well, since "Christ is fully human" is made true by the set of Christ's human possibilities. ${ }^{5}$

This response, however, implies that if such theological possibilities were not closed under logical consequence, then the bi-modal solution would seem counterintuitive. Surely, if "(Possibly) Christ is God-incarnate" entails that there is a divine or human - world where Christ is fully human and fully divine, then it must be the case that Christ is fully human in that world; otherwise, the truth of the conjunction will not rely on the truth of its conjuncts.

Beall and Cotnoir might again reply that "Christ is fully human and fully divine" is actually a conjunction of two (modal) sentences, "(Possibly) Christ is fully human" and "(Possibly) Christ is fully divine". While the whole conjunction is made true by an accessible point in $D$, the first conjunct is made true by a point in $H$ and the second by a point in $D$.

This response, however, begs the question. If each of the conjuncts is in a different set of theological possibility and these sets are not closed under logical consequence, then there will be no reason to infer that their conjunction is in one set and not in another. Furthermore, the bi-modal solution would have no resources of explaining how "(Possibly) Christ is God-incarnate" entails Christ's dual nature if these sets are not closed under logical consequence. ${ }^{6}$

5 This crucial point needs to be answered since if the set of theological possibilities are not closed under logical consequence, then the counterexample developed in this paper will not hold water.

${ }^{6}$ On a more practical point, if the set of possibilities were not closed under logical consequence, then the fundamental problem of orthodox Christology would be moot since the whole issue about the contradictory nature of Christ's mutability and immutability would not even arise. 
Beall and Cotnoir may retort that the proposed bi-modal solution importantly and explicitly distinguishes possibilities that are generally maximal (e.g., modal sentences that are true in worlds) from possibilities that are non-maximal (e.g., the set of theological possibilities within worlds), and that only the latter are accounted for by the bi-modal solution (Beall and Cotnoir, 2020, pp. 4-5). Since there is no compelling reason to evaluate the truth of "(Possibly) Christ is Godincarnate" as a non-maximal (as opposed to a maximal) possibility, the core of the Beall and Cotnoir proposal is left untouched.

This response, however, seems to shift the burden of proof in the dialectic. The dialectic so far has gone from Beall and Cotnoir offering the bi-modal solution as an account of the fundamental problem of Christology to the problem (that I raised here) of how the resources of the bi-modal solution could account for the truth of "(Possibly) Christ is God-incarnate". The response above seems to shift the onus since it asks whether there are reasons to evaluate "(Possibly) Christ is God-incarnate" using the bi-modal account. But there is at least one compelling reason for this: the sentence, "(Possibly) Christ is God-incarnate", expresses a true theological proposition - a proposition that lies in the heart of orthodox Christology. If Beall and Cotnoir aim to have a complete (bi-modal) account of all of these theological propositions, then they should provide an account of the truth of "(Possibly) Christ is God-incarnate" - an account that seems to be left out in their proposed solution.

Beall and Cotnoir may finally respond that the bi-modal solution could be extended to a tri-modal picture, where $T$ will represent the set of (theological) possibilities for the Trinity, and $T$ would have a different sort of accessibility relation and semantic valuation from those of $D$ and $H$. This 
tri-modal picture could account for the sentence, "(Possibly) Christ is God-incarnate" since it belongs to $T$.

This extended tri-modal picture might indeed be a good account for all theological propositions. But until a full, noncircular story of how $T$ relates to $D$ and $H$, the worry about the grounds of the sentence, "(Possibly) Christ is Godincarnate" stands.

\section{Conclusion}

We may grant that Beall and Cotnoir's bi-modal picture provides an explanation of the logical behaviour of the (modal) properties implied by Christ's dual nature. (For example, Christ's mutability is defined in terms of the set of human possibilities and his immutability in terms of the set of divine possibilities.) But while we could grant this much, the picture is, at best, incomplete, or, at worst, self-defeating since it leaves the (modal) grounds of Christ being Godincarnate up for grabs.

\section{References}

BEALL, Jc and COTNOIR, A. J. "Fully divine and fully human: a bi-modal outline towards consistency". Religious Studies, $2020 \quad$ (doi: https://doi.org/10.1017/S0034412520000360)

CROSS, R. “The Incarnation”. In T. P. Flint and M. C. Rea (eds.) (2011), pp. 452-475.

FLINT, T. P., REA, M. C. The Oxford Handbook of Philosophical Theology. Oxford: Oxford University Press, 2011.

BY

Manuscrito - Rev. Int. Fil. Campinas, v. 44, n. 4, pp. 83-92, Oct.-Dec. 2021. 